\title{
Endoscopic and Percutaneous Preoperative Biliary Drainage in Patients with Suspected Hilar Cholangiocarcinoma
}

\author{
Jaap J. Kloek • Niels A. van der Gaag • Yalda Aziz • Erik A. J. Rauws • \\ Otto M. van Delden • Johan S. Lameris • Olivier R. C. Busch • Dirk J. Gouma • \\ Thomas M. van Gulik
}

Received: 5 June 2009/Accepted: 25 August 2009 / Published online: 15 September 2009

(C) 2009 The Author(s). This article is published with open access at Springerlink.com

\begin{abstract}
Introduction Controversy exists over the preferred technique of preoperative biliary drainage (PBD) in patients with hilar cholangiocarcinoma (HCCA) requiring major liver resection. The current study compared outcomes of endoscopic biliary drainage (EBD) and percutaneous transhepatic biliary drainage (PTBD) in patients with resectable HCCA.

Methods One hundred fifteen consecutive patients were explored for HCCA between 2001 and July 2008 and assigned by initial PBD procedure to either EBD or PTBD.

Results Of these patients, 101 (88\%) underwent PBD; 90 patients underwent EBD as primary procedure, and 11 PTBD. The technical success rate of initial drainage was $81 \%$ in the EBD versus $100 \%$ in the PTBD group $(P=0.20)$. Stent dislocation was similar in the EBD and PTBD groups (23\% vs. $20 \%, P=0.70)$. Infectious complications were significantly more common in the endoscopic group ( $48 \%$ vs. $9 \%, P<0.05$ ). Patients in the EBD group underwent more drainage procedures $(2.8$ vs. $1.4, P<0.01)$ and had a significantly longer drainage period until laparotomy (mean 15 weeks vs. 11 weeks in the PTBD group; $P<0.05$ ). In 30 patients, EBD was converted to PTBD due to failure of the endoscopic approach.

Conclusions Preoperative percutaneous drainage could outperform endoscopic stent placement in patients with resectable HCCA, showing fewer infectious complications, using less procedures.
\end{abstract}

Keywords Endoscopic · Percutaneous · Biliary drainage . Cholangiocarcinoma $\cdot$ Preoperative

This work was presented at the Digestive Disease Week, 01-06-2009, Chicago.

Support: there have not been any sources of outside support for this research.

J. J. Kloek • N. A. van der Gaag • Y. Aziz • O. R. C. Busch •

D. J. Gouma $\cdot$ T. M. van Gulik $(\square)$

Department of Surgery, Academic Medical Center, University of Amsterdam,

P. O. Box 22700, 1100 DE, Amsterdam, The Netherlands

e-mail: t.m.vangulik@amc.uva.nl

E. A. J. Rauws

Department of Gastroenterology, Academic Medical Center, University of Amsterdam,

Amsterdam, The Netherlands

O. M. van Delden · J. S. Lameris

Department of Radiology, Academic Medical Center,

University of Amsterdam,

Amsterdam, The Netherlands

\section{Introduction}

Hilar cholangiocarcinoma (HCCA) remains one of the most difficult tumors in terms of staging and radical surgical treatment. ${ }^{1}$ The optimal mode of preoperative management is still under debate. Most patients with HCCA show liver dysfunction caused by obstructive jaundice, which has proven to be a significant risk factor in major liver resection. ${ }^{2-4}$ A potentially fatal complication of extended liver resection in a jaundiced patient is failure of the remnant liver. Therefore, preoperative biliary drainage (PBD) has been devised for jaundiced patients undergoing major hepatic resection to improve the surgical outcome. ${ }^{5,6}$

Controversy exists regarding the preferred technique of $\mathrm{PBD}$, either via endoscopic retrograde biliary drainage (EBD) or using antegrade percutaneous transhepatic biliary drainage (PTBD). PTBD is the preferred method in Japan for relief of obstructive jaundice due to proximal obstruction. ${ }^{7,8}$ In Europe and the USA, EBD is usually performed as primary intervention and is followed by PTBD only 
when EBD has failed. Internal drainage by EBD, although a less invasive technique, carries increased risk of developing cholangitis due to bacterial contamination from the duodenum and increased risk of procedure-related complications such as duodenal perforation and post-EBD, acute pancreatitis. ${ }^{9,10}$ Drainage by means of PTBD is associated with hemobilia, portal vein thrombosis, cancer seeding, and potentially more patient discomfort. ${ }^{11-13}$

The three published prospective randomized controlled trials comparing EBD versus PTBD, included patients with unresectable bile duct tumors or carcinoma of the gallbladder and pancreas showing conflicting results. ${ }^{14-16}$ These studies address palliative treatment and, although important in the context of biliary drainage no, distinction was made between distal and proximal bile duct obstruction. In patients with HCCA with usually involvement of the segmental biliary ducts, drainage of the intrahepatic biliary tree is challenging and mostly requires multiple drains or stents. However, in patients with a distal bile duct obstruction, usually caused by a tumor in the region of the pancreatic head, drainage is more straightforward and requires a single drain or stent. In the latter category of jaundiced patients in whom partial liver resection is usually not undertaken, PBD remains a controversial issue. ${ }^{17,18}$

To date, no studies have been performed regarding the optimal route of drainage in patients with a potentially resectable HCCA. Therefore, the aim of the present study was to compare success rate and complications of EBD and PTBD in patients eligible for resection of a suspected HCCA.

\section{Materials and Methods}

\section{Patients}

A total of 115 patients underwent an explorative laparotomy under the suspicion of HCCA between January 2001 and July 2008, of which 101 (88\%) underwent PBD and were included in the present study (Fig. 1). Fourteen patients did not undergo drainage as their bilirubin level did not exceed $40 \mu \mathrm{mol} / \mathrm{L}$. Usually, resectional surgery was performed when serum bilirubin levels had decreased to $\leq 40 \mu \mathrm{mol} / \mathrm{L}$. When feasible, hilar resection with complete lymphadenectomy of the hepatoduodenal ligament was performed, usually en bloc with (extended) hemihepatectomy, caudate lobe resection and the portal vein bifurcation when involved by tumor. ${ }^{19}$ Unresectable disease, due to vascular ingrowth and/or (extra) hepatic metastases, was confirmed histologically. Patients were divided into two groups according to the primary drainage procedure; PTBD or EBD. In the majority of the included patients, the initial diagnostic evaluation and drainage procedures were per-

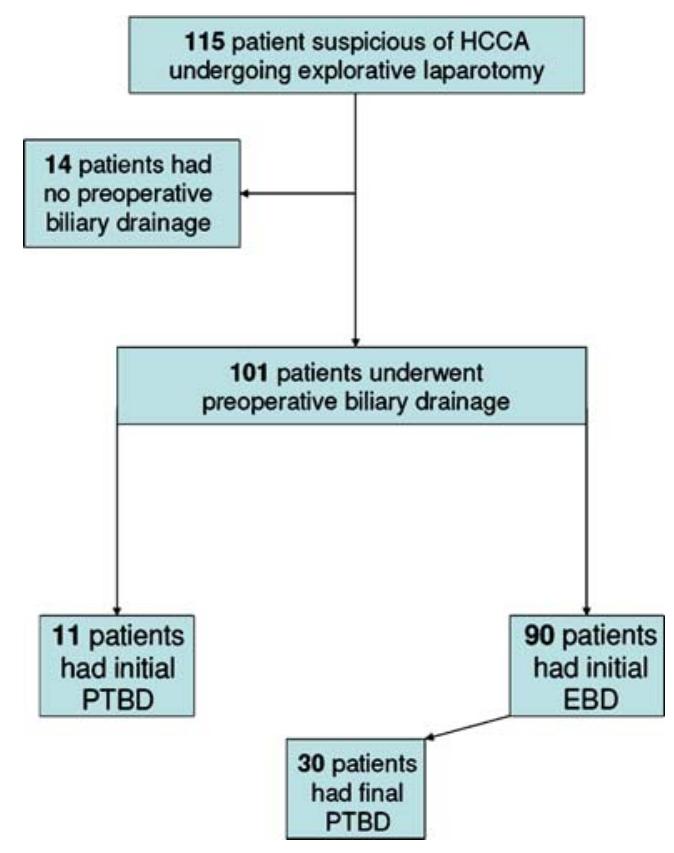

Figure 1 Flow chart of patients eligible for resection of hilar cholangiocarcinoma (HCCA) in the period from January 2001 to July 2008.

formed in the referring hospitals. Medical data of patients collected from these hospitals and from our tertiary referring center included demographic features, laboratory investigations, results of imaging studies, results of EBD and PTBD, and intra-operative findings.

\section{Staging of HCCA}

Proximal obstruction in the biliary tract was staged according to the Bismuth-Corlette classification based on all available imaging studies. ${ }^{20}$ Bismuth type I and II tumors obstruct the proximal common hepatic duct or hepatic duct confluence, but do not extend into the intrahepatic segmental ducts; Type IIIa/b tumors involve the hepatic duct confluence and extend into the right or left segmental intrahepatic branches; Type IV tumors involve the hepatic duct confluence with extension into both the right and left segmental branches.

\section{Biliary Decompression}

The technique of PTBD in this series involves the use of ultrasound guidance, a thin Chiba needle and a 0.014-in. guidewire to gain access to the biliary system. Antegrade cholangiography was performed to localize the site of obstruction, after which the guidewire was advanced through the stenosis. Thereafter, a catheter was placed with its distal end in the duodenum for internal-external drainage. The bile was collected for the first $48 \mathrm{~h}$, after which the catheter was closed in order to achieve internal drainage. 
For EBD, straight Amsterdam type polyethylene stents were used. ${ }^{21}$ After a small sphincterotomy to facilitate introduction of the various catheters a retrograde cholangiography was performed to localize the site of obstruction. The guidewire was maneuvered through and above the biliary stenosis followed by a catheter. The endoprosthesis was then pushed in position over the catheter. The guidewire, catheter, and endoscope were removed, leaving the polyethylene stent in situ. When insertion of two stents was required during the same session, two guidewires were placed before insertion of the first stent. Radiological imaging was not part of routine drainage procedure planning.

\section{Definition of Events}

Technical success was defined as stent/catheter insertion across the stricture with appropriate position and immediate biliary decompression. Infectious complications comprised cholangitis and/or cholecystitis. Cholangitis was defined as a temperature $>38.5^{\circ} \mathrm{C}$ without another demonstrable cause that persisted for longer than $24 \mathrm{~h}$, together with biochemical evidence of cholestasis and infection (increased C-reactive protein and leucocytes). Cholecystitis was diagnosed on the basis of right upper quadrant pain, along with supportive evidence on imaging studies. Acute pancreatitis was defined as persistent abdominal pain with three times or more elevation of serum amylase levels. ${ }^{10}$ Stent dysfunction (occlusion, migration, or failure) was scored when persistence or recurrence of jaundice was determined and/or imaging studies showed evidence of dilated segmental biliary ducts. Biliary re-intervention was defined as any type of endoscopic or percutaneous procedure that was required to improve biliary drainage after stent insertion. Finally, therapeutic success was defined when an almost normal range bilirubin level $(\leq 40 \mu \mathrm{mol} / \mathrm{L})$ was achieved at the time of last plasma bilirubin measurement before surgery. All abovementioned events were taken into account during the period from the first attempt of drainage until explorative laparotomy.

\section{Intention to Treat Analysis}

We assessed the effect of the biliary drainage procedures using the following variables: technical success of stent insertion, infectious complications, stent migration, number of procedures, interval from first drainage attempt until explorative laparotomy, and therapeutic success. For the intention-to-treat analysis, we assigned subjects by initial drainage procedure $(n=101)$ to the EBD group or PTBD group. The EBD group included also patients in whom EBD was finally converted to PTBD, because of technical failure (including no drainage of the future remnant liver) and/or recurrence of complications.

\section{Statistics}

Statistical analysis was performed using the Statistical Package for Social Sciences 14.0 (SPSS, Chicago, Illinois, USA). Mean $\pm \mathrm{SD}$, or median with range if not normally distributed, described continuous parameters. Student's $t$ test, Mann-Whitney $U$ test, or Fisher's exact test were used where appropriate, analyzing the differences in the various parameters between groups. A $P$ value of $<0.05$ was considered statistically significant.

\section{Results}

\section{Patient Characteristics}

Table 1 shows the baseline characteristics of 101 patients undergoing PBD: 90 patients underwent EBD as primary procedure and 11 patients PTBD. The median age, malefemale ratio, and the extent of bile duct involvement classified according to the Bismuth staging system did not differ significantly between groups. No differences were observed in plasma bilirubin levels before drainage. The diagnosis as confirmed by histopathological assessment of the resection specimen or of biopsies in the nonresected patients was equally distributed between the EBD and PTBD group. There was a difference between both groups in the type of hospital where the initial drainage procedure was undertaken. In the PTBD group more initial procedures $(6 / 11)$ were performed in a tertiary care center $(P=0.01)$. Surgical outcome was not different between both groups in terms of morbidity and mortality (data not shown).

\section{Technical and Therapeutic Success}

Initial drainage was technically successful in $73(81 \%)$ patients in the EBD versus $11(100 \%)$ patients in the PTBD group $(P=0.203$, Table 2$)$. In all patients in the PTBD group, internal biliary drainage was achieved by passing the catheter across the tumor site, into the duodenum. With regard to the 17 patients in the endoscopic group in whom the initial procedure failed, this was due to patient agitation $(n=2)$, procedure-related complications $(n=2$, severe sphincterotomy bleeding and duodenal perforation, respectively) and difficulties in passing the stricture $(n=13)$. In eight of these 17 patients, endoscopic stent placement succeeded at a subsequent attempt. The other nine patients were either directly switched to PTBD or after failure of subsequent endo- 
Table 1 Characteristics of 101 Patients Undergoing PBD Suspicious of Resectable HCCA

$P B D$ preoperative biliary drainage, $E B D$ endoscopic biliary drainage, $P T B D$ percutaneous transhepatic biliary drainage

${ }^{\text {a }} P$ value is $\mathrm{PTBD}$ vs. EBD (Fisher's exact test or MannWhitney $U$ test)

\begin{tabular}{llll}
\hline & PTBD $(n=11)$ & EBD $(n=90)$ & $P$ value $^{\mathrm{a}}$ \\
\hline Gender male-female & $6-5$ & $64-26$ & 0.305 \\
Median age (range) & $61(36-75)$ & $61(37-77)$ & 0.870 \\
Mean plasma bilirubin pre drainage & $231( \pm 140)$ & $177( \pm 112)$ & 0.231 \\
Bismuth classification & & & 0.837 \\
$\quad$ Type I, II & $3(27 \%)$ & $22(25 \%)$ & \\
Type III, IV & $8(73 \%)$ & $68(75 \%)$ & 0.237 \\
Final pathological diagnosis & & & \\
$\quad$ Cholangiocarcinoma & $8(73 \%)$ & $80(89 \%)$ & \\
$\quad$ Metastatic disease & - & $1(1 \%)$ & 0.012 \\
$\quad$ Benign stricture & $3(27 \%)$ & $9(10 \%)$ & $16-74$ \\
Initial procedure tertiary-referring hospital & $6-5$ & & \\
\hline
\end{tabular}

scopic attempts. Further procedure-related complications other than failure of drainage, were bile duct perforation in one patient in the EBD group and hemobilia in the PTBD group. The mean number of drains/stents in situ before surgery to achieve sufficient drainage of at least the future remnant liver was 1.4 (range 1-3) in the PTBD group and $1.7(1-4)$ in the endoscopic group $(P=0.134)$. Therapeutic success was equally effective since the plasma bilirubin levels before laparotomy were similar in both groups (Table 2).

\section{Complications}

The distribution of complications in both groups is shown in Table 2. The most frequent complication was cholangitis which occurred significantly more often in the EBD group. Forty-eight percent of the patients in the EBD group had one or more infectious complications compared to $9 \%$ in the PTBD group $(P=0.021)$. Another infectious complication was acute cholecystitis which occurred in one patient of the EBD group. This patient was treated successfully by percutaneous drainage of the gallbladder until laparotomy. Although the rate of one or more stent dislocations per patient was similar in the EBD and PTBD groups $(23 \%$ vs. $20 \%, P=0.701)$, the number of reinterventions required to manage infectious and stentrelated problems was significantly increased in the EBD group compared to the PTBD group (2.8 vs. $1.4, P<0.01)$. The increased number of infectious complications in the EBD group resulted in a longer mean drainage period until explorative laparotomy, namely 15 weeks (min-max 4$29)$ in comparison to 11 weeks (3-21) in the PTBD group $(P=0.033)$. Furthermore, other complications were recorded such as acute pancreatitis $(n=7)$, hemobilia $(n=1)$, and biliary perforation $(n=1)$. Pancreatitis was only observed in the EBD group. In one patient after an endoscopic procedure, a bile duct perforation resulted in severe peritonitis, sepsis, and admission to the intensive
Table 2 Clinical Outcome of Patients After PBD via the Endoscopic or Percutaneous Approach

$E B D$ endoscopic biliary drainage, $P T B D$ percutaneous transhepatic biliary drainage

${ }^{\text {a }} P$ value is PTBD vs. EBD (Fisher's exact test or MannWhitney $U$ test)

\begin{tabular}{llll}
\hline & PTBD $(n=11)$ & EBD $(n=90)$ & $P$ value $^{\mathrm{a}}$ \\
\hline Technical success stent insertion & $11(100 \%)$ & $73(81 \%)$ & 0.203 \\
Complications & $1(9 \%)$ & $43(48 \%)$ & 0.021 \\
Infectious & 1 & 43 & \\
Cholangitis & - & 1 & 0.701 \\
Acute cholecystitis & $2(20 \%)$ & $21(23 \%)$ & \\
Dislocation & - & 7 & \\
Other & 1 & - & \\
Pancreatitis & - & 1 & 0.033 \\
Hemobilia & - & 1 & 0.001 \\
Duodenal perforation & $11(3-21)$ & $15(4-29)$ & 0.134 \\
Biliary perforation & $1.4(1-3)$ & $1.7(1-4)$ & \\
Wks drainage $\rightarrow$ laparotomy (range) & $1.4(1-3)$ & $23( \pm 21)$ & \\
Mean no. of procedures (range) & $18( \pm 14)$ & & \\
Mean no. of stents in situ (range) & & & \\
Mean plasma bilirubin pre-laparotomy & &
\end{tabular}


care unit. Transient hemobilia occurred in one patient in the PTBD group, but required no blood transfusion.

\section{Patients Treated with Both Procedures}

The EBD group included patients in whom the endoscopic interventions were finally converted to PTBD. In total 30 patients were switched including the nine abovementioned patients in whom initial endoscopic drainage had failed. Conversion to PTBD was mainly due to recurrence of complications and in three patients $(10 \%)$ because the endoscopic approach had failed to drain the future remnant liver. In $10(33 \%)$ patients in whom endoscopic stent placement was eventually converted to the percutaneous approach, one single PTBD procedure sufficed until explorative laparotomy. One severe complication occurred after a PTBD procedure, namely portal vein thrombosis which rendered the patient unresectable as determined during explorative laparotomy. The rate of infectious complications in patients with mixed procedures was $67 \%$. Sixteen (53\%) of the 30 switched patients had one or more stent dislocations, resulting in a mean number of 4.2 (range 2-7) procedures per patient. Finally, the mean drainage period until explorative laparotomy was 15 weeks (min-max 5-26 weeks). The number of stent dislocations in the switched group comprised the sum of endoscopic and percutaneous migrated stents, whereas in the analysis of the EBD group (the abovementioned 90 patients) only the endoscopic-migrated stents were included. Concerning infectious complications no distinction was made because after a mix of different approaches it is difficult to assess which procedure initially caused the infection.

\section{Discussion}

The results of the present study show a more favorable outcome of PTBD than of EBD for PBD in patients with potentially resectable HCCA. EBD is associated with more infectious complications resulting in a higher number of procedures and finally a longer work-up period until explorative laparotomy. We are aware of the limitations of the present study; a retrospective analysis and unequal distribution of patient number in the treatment groups. However, to our knowledge, no other studies are available comparing endoscopic with percutaneous biliary drainage in patients with potentially resectable HCCA. As in the earlier mentioned prospective trials, ${ }^{14-16}$ the results of a recently published retrospective study about this issue was in the setting of palliative treatment. ${ }^{22}$

In the diagnostic strategy of hilar lesions accuracy of computed tomography or magnetic resonance cholangiography is known to be higher when performed prior to stent placement, due to prevention of endoprosthesis scattering artifacts. Correct staging according to the Bismuth classification has shortcomings for determining resectability of tumors, ${ }^{23}$ but is useful in deciding a proper biliary drainage strategy, i.e. the future liver remnant. Moreover, this highly improves the success of subsequent stent placement. ${ }^{24,25}$ Interventional radiologists are more likely to perform preprocedural imaging themselves and therefore, benefit from this information. Although considered an obsolete procedure for diagnostic purposes, endoscopic retrograde cholangiography is nevertheless still regularly performed before radiological imaging in the evaluation of obstructive jaundice. This might at least in part explain the high number of EBD procedures used as initial mode in this series.

Tumors of the proximal bile ducts are rare and the varying experience of the endoscopist during the initial drainage procedure could have biased the outcome of this study. Most initial procedures in the PTBD group were performed in a tertiary referring center (i.e. AMC) with consequently, greater case load and experienced interventional radiologists. A number of surgical studies have shown a relationship between procedural volumes of an institution and patient outcomes. ${ }^{26,27}$ This relationship has been most consistent for complex procedures and along the same lines, seems to hold true on the level of interventions for biliary drainage, ${ }^{28}$ especially in cases of hilar bile duct tumors.

Cholangitis due to bacterial contamination originating from the duodenum is a serious clinical problem which often requires additional interventions. Cholangitis after PTBD is also possible especially when extended to internal drainage. A $48 \%$ infectious complication rate after EBD is comparable with other series in the literature, ${ }^{9,29}$ albeit drawing a parallel between these studies is difficult depending on applied definitions of infectious complications. A 9\% infectious rate after PTBD is low and could be biased by the small number of patients included in this group although comparable rates have been described after PTBD in larger series in the literature. ${ }^{30}$ Acute pancreatitis, however uncommon, is a potentially severe complication which was only observed in the EBD group. The increased infection rate probably explains the significantly higher number of necessary re-interventions in the EBD group in comparison to the PTBD group.

Stent migration is another important complication requiring re-intervention. With self-expanding metal stents, dislodgement of the stent is exceptional, ${ }^{31}$ but its use is generally confined to unresectable disease. In the present study, polyethylene endoprostheses were used because patients were all potentially resectable. Stent dislodgement in the endoscopic and percutaneous group occurred around $20 \%$, which is rather high in comparison to other 
studies. $^{32,33}$ Apart from the high migration incidence we can conclude that the approach, either by EBD or by PTBD, had no influence on stent patency.

Which part of the liver should be drained is an ongoing controversy. ${ }^{12,32}$ Pre-procedural planning should involve evaluation of the exact level and extension of the stricture site, selection of the most appropriate liver segments for drainage and assessment of an appropriate access route. PTBD offers the possibility to perform selective biliary drainage (SBD) whereas EBD via both the left and right hepatic duct often implies total biliary drainage (TBD). An argument for SBD of the future remnant liver is the subsequent induction of hypertrophy on this side of the liver, and atrophy of the non-drained part of the liver to be resected. $^{34,35}$ In a retrospective cohort study in which the effect of SBD versus TBD was investigated before hepatectomy in 42 patients, SBD was not found to increase the risk of cholangitis. ${ }^{36}$ In association with portal vein embolization, SBD proved superior to TBD in promoting hypertrophy of the future remnant liver, by which extended hemihepatectomy could be performed more safely. The only existing prospective randomized controlled trial comparing TBD versus SBD included patients with unresectable hilar bile duct tumors. ${ }^{37}$ Unilateral drainage resulted in a higher technical success rate of stent insertion and a significantly lower incidence of complications. The above studies showed better results for SBD and therefore indirectly indicated a preference for PTBD through which segmental drainage is more easily achieved.

In our study we did not evaluate the cost-effectiveness of both procedures. From other studies in literature it is known that the number of re-interventions is an important factor influencing the final costs. In three studies for example, metallic stents were compared with plastic endoprostheses. ${ }^{33,38,39}$ The initial high costs made in the group with metallic stents, were counterbalanced by the reduction in the need for endoscopic re-interventions and/or rehospitalization. Therefore, the number of extra procedures needed is a significant factor in the comparison of costs and, based on our results, suggests a preference for the PTBD group. The introduction of costs into the decisionmaking process is of course, only justified when both procedures under consideration have equal clinical benefit.

From a surgical point of view, preoperative PTBD may have an additional advantage during exploration of the hilar area of the liver. In the authors' experience, the biliary tubes help to define the bile ducts proximal of the tumor in the operative field and to guide the parenchymal dissection at a safe distance of the tumor. Also, when the resection has taken place and the biliary ducts of the liver remnant are anastomosed to a Roux-en-Y jejunal loop, the PTBD tubes are shortened and used as transanastomotic drains to facilitate healing of the hepaticojejunostomies. After a control cholan- giography via the PTBD tubes at 3-6 weeks postoperatively, the tubes are removed. In case of EBD, the stents are removed during resection and new transanastomotic biliary drains are placed, usually in a retrograde fashion.

In conclusion, our results indicate that preoperative percutaneous biliary drainage could outperform endoscopic stent placement in patients with resectable HCCA, showing fewer infectious complications resulting in significantly less procedures. These results underline the importance of further (randomized) studies to confirm this point, which should be conducted in specialized centers with experience in the preoperative work-up of this relatively rare tumor.

Open Access This article is distributed under the terms of the Creative Commons Attribution Noncommercial License which permits any noncommercial use, distribution, and reproduction in any medium, provided the original author(s) and source are credited.

\section{References}

1. Lazaridis KN, Gores GJ. Cholangiocarcinoma. Gastroenterology 2005; $128: 1655-1667$.

2. Dixon JM, Armstrong CP, Duffy SW, Davies GC. Factors affecting morbidity and mortality after surgery for obstructive jaundice: a review of 373 patients. Gut 1983;24:845-852.

3. Blamey SL, Fearon KC, Gilmour WH, Osborne DH, Carter DC. Prediction of risk in biliary surgery. Br J Surg 1983;70:535-538.

4. Shigeta H, Nagino M, Kamiya J, Uesaka K, Sano T, Yamamoto H, Hayakawa N, Kanai M, Nimura Y. Bacteremia after hepatectomy: an analysis of a single-center, 10-year experience with 407 patients. Langenbecks Arch Surg 2002;387:117-124.

5. Saiki S, Chijiiwa K, Komura M, Yamaguchi K, Kuroki S, Tanaka M. Preoperative internal biliary drainage is superior to external biliary drainage in liver regeneration and function after hepatectomy in obstructive jaundiced rats. Ann Surg 1999;230:655-662.

6. Gouma DJ, Roughneen PT, Kumar S, Moody FG, Rowlands BJ. Changes in nutritional status associated with obstructive jaundice and biliary drainage in rats. Am J Clin Nutr 1986;44:362-369.

7. Nimura Y. Preoperative biliary drainage before resection for cholangiocarcinoma (Pro). HPB (Oxford) 2008;10:130-133.

8. Kawasaki S, Imamura H, Kobayashi A, Noike T, Miwa S, Miyagawa S. Results of surgical resection for patients with hilar bile duct cancer: application of extended hepatectomy after biliary drainage and hemihepatic portal vein embolization. Ann Surg 2003;238:84-92.

9. dos Santos JS, Junior WS, Modena JL, Brunaldi JE, Ceneviva R. Effect of preoperative endoscopic decompression on malignant biliary obstruction and postoperative infection. Hepatogastroenterology 2005;52:45-47.

10. Cotton PB, Lehman G, Vennes J, Geenen JE, Russell RC, Meyers WC, Liguory C, Nickl N. Endoscopic sphincterotomy complications and their management: an attempt at consensus. Gastrointest Endosc 1991;37:383-393.

11. van Delden OM, Lameris JS. Percutaneous drainage and stenting for palliation of malignant bile duct obstruction. Eur Radiol 2008;18:448-456.

12. Maguchi H, Takahashi K, Katanuma A, Osanai M, Nakahara K, Matuzaki S, Urata T, Iwano H. Preoperative biliary drainage for 
hilar cholangiocarcinoma. J Hepatobiliary Pancreat Surg 2007;14:441-446.

13. Sakata J, Shirai Y, Wakai T, Nomura T, Sakata E, Hatakeyama K. Catheter tract implantation metastases associated with percutaneous biliary drainage for extrahepatic cholangiocarcinoma. World J Gastroenterol 2005;11:7024-7027.

14. Pinol V, Castells A, Bordas JM, Real MI, Llach J, Montana X, Feu F, Navarro S. Percutaneous self-expanding metal stents versus endoscopic polyethylene endoprostheses for treating malignant biliary obstruction: randomized clinical trial. Radiology 2002;225:27-34.

15. Speer AG, Cotton PB, Russell RC, Mason RR, Hatfield AR, Leung JW, MacRae KD, Houghton J, Lennon CA. Randomised trial of endoscopic versus percutaneous stent insertion in malignant obstructive jaundice. Lancet 1987;2:57-62.

16. Saluja SS, Gulati M, Garg PK, Pal H, Pal S, Sahni P, Chattopadhyay TK. Endoscopic or percutaneous biliary drainage for gallbladder cancer: a randomized trial and quality of life assessment. Clin Gastroenterol Hepatol 2008;6:944-950.

17. van der Gaag NA, de Castro SM, Rauws EA, Bruno MJ, van Eijck CH, Kuipers EJ, Gerritsen JJ, Rutten JP, Greve JW, Hesselink EJ, Klinkenbijl JH, Borel RI, Boerma D, Bonsing BA, van Laarhoven CJ, Kubben FJ, van der HE, Sosef MN, Bosscha K, de Hingh IHJT, de Wit LT, van Delden OM, Busch OR, van Gulik TM, Bossuyt PM, Gouma DJ. Preoperative biliary drainage for periampullary tumors causing obstructive jaundice; DRainage vs. (direct) OPeration (DROP-trial). BMC Surg 2007;7:3.

18. Wang Q, Gurusamy KS, Lin H, Xie X, Wang C. Preoperative biliary drainage for obstructive jaundice. Cochrane Database Syst Rev 2008; CD005444.

19. van Gulik TM, Dinant S, Busch OR, Rauws EA, Obertop H, Gouma DJ. Original article: new surgical approaches to the Klatskin tumour. Aliment Pharmacol Ther 2007;26:127-132.

20. Bismuth $\mathrm{H}$, Corlette MB. Intrahepatic cholangioenteric anastomosis in carcinoma of the hilus of the liver. Surg Gynecol Obstet 1975;140:170-178

21. van Berkel AM, Boland C, Redekop WK, Bergman JJ, Groen AK, Tytgat GN, Huibregtse K. A prospective randomized trial of Teflon versus polyethylene stents for distal malignant biliary obstruction. Endoscopy 1998;30:681-686.

22. Paik WH, Park YS, Hwang JH, Lee SH, Yoon CJ, Kang SG, Lee JK, Ryu JK, Kim YT, Yoon YB. Palliative treatment with selfexpandable metallic stents in patients with advanced type III or IV hilar cholangiocarcinoma: a percutaneous versus endoscopic approach. Gastrointest Endosc 2009;69:55-62.

23. Jarnagin WR, Fong Y, DeMatteo RP, Gonen M, Burke EC, Bodniewicz BJ, Youssef BM, Klimstra D, Blumgart LH. Staging, resectability, and outcome in 225 patients with hilar cholangiocarcinoma. Ann Surg 2001;234:507-517.

24. Hintze RE, bou-Rebyeh H, Adler A, Veltzke-Schlieker W, Felix R, Wiedenmann B. Magnetic resonance cholangiopancreatographyguided unilateral endoscopic stent placement for Klatskin tumors. Gastrointest Endosc 2001;53:40-46.
25. Freeman ML, Overby C. Selective MRCP and CT-targeted drainage of malignant hilar biliary obstruction with selfexpanding metallic stents. Gastrointest Endosc 2003;58:41-49.

26. Luft HS, Bunker JP, Enthoven AC. Should operations be regionalized? The empirical relation between surgical volume and mortality. N Engl J Med 1979;301:1364-1369.

27. Dimick JB, Cowan JA Jr, Knol JA, Upchurch GR Jr. Hepatic resection in the United States: indications, outcomes, and hospital procedural volumes from a nationally representative database. Arch Surg 2003;138:185-191.

28. Kapral C, Duller C, Wewalka F, Kerstan E, Vogel W, Schreiber F. Case volume and outcome of endoscopic retrograde cholangiopancreatography: results of a nationwide Austrian benchmarking project. Endoscopy 2008;40:625-630.

29. Rerknimitr R, Kladcharoen N, Mahachai V, Kullavanijaya P. Result of endoscopic biliary drainage in hilar cholangiocarcinoma. J Clin Gastroenterol 2004;38:518-523.

30. Stoker J, Lameris JS, van BM. Percutaneous metallic selfexpandable endoprostheses in malignant hilar biliary obstruction. Gastrointest Endosc 1993;39:43-49.

31. Fumex F, Coumaros D, Napoleon B, Barthet M, Laugier R, Yzet T, Le SA, Desurmont P, Lamouliatte H, Letard JC, Canard JM, Prat F, Rey JF, Ponchon T. Similar performance but higher cholecystitis rate with covered biliary stents: results from a prospective multicenter evaluation. Endoscopy 2006;38:787-792.

32. Chang WH, Kortan P, Haber GB. Outcome in patients with bifurcation tumors who undergo unilateral versus bilateral hepatic duct drainage. Gastrointest Endosc 1998;47:354-362.

33. Wagner HJ, Knyrim K, Vakil N, Klose KJ. Plastic endoprostheses versus metal stents in the palliative treatment of malignant hilar biliary obstruction. A prospective and randomized trial. Endoscopy 1993;25:213-218.

34. Miyagawa S, Makuuchi M, Kawasaki S. Outcome of extended right hepatectomy after biliary drainage in hilar bile duct cancer. Arch Surg 1995;130:759-763.

35. Hadjis NS, Adam A, Gibson R, Blenkharn JI, Benjamin IS, Blumgart LH. Nonoperative approach to hilar cancer determined by the atrophy-hypertrophy complex. Am J Surg 1989;157:395-399.

36. Ishizawa T, Hasegawa K, Sano K, Imamura H, Kokudo N, Makuuchi M. Selective versus total biliary drainage for obstructive jaundice caused by a hepatobiliary malignancy. Am J Surg 2007;193:149-154.

37. De Palma GD, Galloro G, Siciliano S, Iovino P, Catanzano C. Unilateral versus bilateral endoscopic hepatic duct drainage in patients with malignant hilar biliary obstruction: results of a prospective, randomized, and controlled study. Gastrointest Endosc 2001;53:547-553.

38. Soderlund C, Linder S. Covered metal versus plastic stents for malignant common bile duct stenosis: a prospective, randomized, controlled trial. Gastrointest Endosc 2006;63:986-995.

39. Yeoh KG, Zimmerman MJ, Cunningham JT, Cotton PB. Comparative costs of metal versus plastic biliary stent strategies for malignant obstructive jaundice by decision analysis. Gastrointest Endosc 1999;49:466-471. 